\title{
Knee degeneration in concrete reinforcement workers
}

\author{
G WICKSTRÖM, ${ }^{1} \mathrm{~K}$ HÄNNINEN, ${ }^{2}$ T MATTSSON,${ }^{1}$ T NISKANEN, ${ }^{1}$ H RIIHIMÄKI, ${ }^{2}$ \\ P WARIS, ${ }^{1}$ AND A ZITTING ${ }^{1}$ \\ From the Institute of Occupational Health ${ }^{1}$ and the Employment Pension Fund, ${ }^{2}$ Helsinki, Finland
}

ABSTRACT The loads on the knees in concrete reinforcement work and maintenance painting were analysed on eight construction work sites. A total of 352 reinforcement workers and 231 painters, Finnish men aged 20-64, were clinically and radiologically examined to determine the condition of the knee joints in active workers. The loads on the knees and the occurrence of minor injuries and accidents were higher in reinforcement work than in painting, but the occurrence of symptoms, clinical signs, and radiological findings was equally common in both groups. Reinforcement work seemed to provoke more symptoms from degenerated knees than painting.

There are few studies of the occurrence of meniscal lesions and arthritic changes in the knee joints in specific occupational groups. Coal miners have been studied extensively and been found to have an unusually common occurrence of bursitis around the knee $^{12}$ as well as meniscal lesions and arthrosis. ${ }^{3-9}$ Workers doing heavy carrying also have radiological signs of knee arthrosis more commonly than would be expected. ${ }^{10}$

We have carried out a large epidemiological study to determine the effects of concrete reinforcement work on the musculoskeletal system of the workers. " We report the findings from the knee joints.

\section{Material and methods}

\section{ANALYSIS OF WORK LOADS}

The physical loads on the musculoskeletal system in the reinforcement trade were determined through systematic observation on six work sites (two bridge, two building, and two dwelling house construction sites). An engineer and a physiotherapist together recorded postures and handling of weights at 30 second intervals according to a scheme developed for this purpose. The postures of the legs were divided into 10 classes and the handling of weights into three; the observations covered 210 active working hours. The occurrence of sudden minor injury (causing no or less than one day of sick leave) was determined through interviews with 75 workers at one to two week intervals. The incidence of work accidents causing sick leave was established for all

Received 19 April 1982

Accepted 7 June 1982
Finnish reinforcement workers from register data on insurance benefits.

For comparison, work postures and handling of weights were investigated using the same methods on two maintenance painting sites for 60 active working hours. The occurrence of minor injuries and the incidence of work accidents in maintenance painting were also determined. ${ }^{12}$

\section{EXAMINATION OF WORKERS}

The musculoskeletal system of the workers active in the concrete reinforcement trade in Uusimaa county was clinically examined in 252 of the 295 men constituting this group (participation $85 \%$ ). All were Finnish men aged $20-64$. Their mean age was 41 , and their mean work experience 15 years. Their work experience outside the reinforcement trade mostly consisted of work in other physically heavy occupations in agriculture, forestry, and the construction industry.

A group of 231 male maintenance painters (participation $86 \%$ ) were also examined to serve as a comparison group. Their mean age was 42 (range 24-64), and their mean experience of painting work, 21 years. $^{13}$

The examination of the workers consisted of an interview, and a physical and a radiological examination. The interview was carried out according to a standardised questionnaire immediately before the clinical examination of the musculoskeletal system. The questions concerned previous and present knee symptoms, knee accidents, and sick leave due to knee disorders. The clinical examination was performed by two experienced physiotherapists, espe216 
cially trained for this investigation. The examination consisted of various tests for stability and movement of the knee joints, as well as tests for provoking symptoms. On analysing the results afterwards, no systematic difference was found between the physiotherapists.

The radiological examination consisted of one anteroposterior and one lateral film of both knees taken in the supine position. The two radiologists of the radiological department of the Institute of Occupational Health read all the films. At first the films were looked through to get an opinion of the severity of the degenerative changes in the material. On the basis of this survey, a classification scheme was devised with a four-step grading (no, mild, moderate, and severe changes) that would fit the material. Some films were picked out to represent the different categories as reference films.

After this, a pilot study, in which the radiologists read the films of 50 workers independently, was carried out to determine the inter-observer error between the two radiologists when using this classification scheme. All films were read without knowledge of personal data (age, occupation) or date of examination. In the definite classification of the findings the two radiologists read the films together and decided on the findings in consensus.

The results were adjusted for age before comparison between the two occupational groups. The Mantel-Haenszel test was used for significance testing. ${ }^{14}$

\section{Results}

WORK LOADS

Standing with bent knees was more frequent in reinforcement work than in painting, while squatting was more common in painting work (table 1). Handling of weights implied higher loads on the knee joints of the reinforcement workers than on the knees of the painters. The reinforcement workers lifted a load of 5-20 kg 15 times an hour, while the painter lifted such a load only six times an hour. The reinforcement workers lifted a load of over $20 \mathrm{~kg}$ six times an hour while the painters seldom lifted such heavy loads.

The work surfaces caused difficulties for both reinforcement workers and painters. In reinforcement work steel rods lying flat on the surfaces and ends of steel rods sticking up caused uneven surfaces. As the work is done out of doors the work surfaces are often slippery during winter time. The painters often worked on platforms, which implied frequent ascending and descending. The work surfaces were classified as somewhat difficult (obstacles or working on platform) in $40 \%$ of the observations
Table 1 Postures and movements of legs in reinforcement and painting work

\begin{tabular}{lcc}
\hline $\begin{array}{l}\text { Posture or } \\
\text { movement }\end{array}$ & $\begin{array}{l}\text { Reinforcement } \\
\text { work 25 108 } \\
\text { observations (\%) }\end{array}$ & $\begin{array}{l}\text { Painting } \\
7512 \text { observations } \\
(\%)\end{array}$ \\
\hline $\begin{array}{l}\text { Standing straight, weight } \\
\quad \text { on both feet }\end{array}$ & 75 & 76 \\
$\begin{array}{l}\text { Standing with weight on } \\
\text { one foot }\end{array}$ & 3 & 4 \\
Standing with bent knees & 3 & 0 \\
Squatting & 2 & 9 \\
On one or both knees & 4 & 3 \\
Sitting & 1 & 1 \\
Lying & 0 & 0 \\
Walking & 11 & 5 \\
Moving & 1 & 1 \\
Ascending or descending & 0 & 1 \\
platform or staircase & 100 & 100 \\
\hline
\end{tabular}

of reinforcement work and in $30 \%$ of those of painting. The corresponding figures for difficult (unsure, slippery) surfaces were $15 \%$ for reinforcement work compared with $5 \%$ for painting.

Minor injuries were reported five times more frequently by the reinforcement workers $(1.9$ minor injury/1000 working hours) than by painters $(0 \cdot 38$ minor injury/ 1000 working hours). Slipping and stumbling were responsible for $70 \%$ of the minor injuries among the reinforcement workers compared with only $8 \%$ among the painters, while stepping down or falling from platforms was more common among painters $(36 \%)$ than among reinforcement workers $(10 \%)$.

The register on work accidents does not differentiate between knee accidents and other accidents to the legs. The incidence of work accidents affecting the whole musculoskeletal system was twice as high among the reinforcement workers as among the painters. In both trades a quarter of these accidents affected the legs.

\section{KNEE SYMPTOMS AND FINDINGS}

In the interview an accident to the knee at some time was reported by $27 \%$ of both reinforcement workers and painters. A third of these men said that they still had knee trouble at times because of this. The occurrence of knee accidents during the 12 months before this investigation was reported equally $(8 \%)$ by both groups. Of the reinforcement workers, $5 \%$ had been on sick leave because of knee trouble during the previous 12 months compared with $3 \%$ of the painters.

Knee symptoms during the preceding month were as common in painters as in reinforcement workers (table 2). The occurrence of stiffness and especially the occurrence of pain or ache became more common with advancing age, while sick leave due to knee trouble was equally common in all age groups. 
Table 2 Knee symptoms during preceding month in reinforcement workers and painters

\begin{tabular}{lll}
\hline Symptom & $\begin{array}{l}\text { Reinforcement } \\
\text { workers }(n=252)\end{array}$ & $\begin{array}{l}\text { Painters }(n=231) \\
(\%)\end{array}$ \\
\hline Pain or ache & 25 & 30 \\
Stiffness & 21 & 18 \\
Locking & 8 & 7 \\
\hline
\end{tabular}

Table 3 Clinical findings from the knee joints in reinforcement workers and painters

\begin{tabular}{llc}
\hline Clinical finding & $\begin{array}{l}\text { Reinforcement } \\
\text { workers } \\
(n=252)(\%)\end{array}$ & $\begin{array}{l}\text { Painters } \\
(n=231)(\%)\end{array}$ \\
\hline Crepitation & 39 & 44 \\
$\begin{array}{l}\text { Patellar tenderness } \\
\text { Tenderness on palpation } \\
\text { of medial joint fissure }\end{array}$ & 21 & 18 \\
$\begin{array}{l}\text { Tenderness on palpation } \\
\text { of lateral joint fissure }\end{array}$ & 8 & 4 \\
$\begin{array}{l}\text { Diminished flexion } \\
\text { Hyperextension }\end{array}$ & 4 & 3 \\
\hline
\end{tabular}

Table 4 Radiologically detectable degenerative changes in the knee joints of reinforcement workers and painters

\begin{tabular}{llr}
\hline Degenerative change & $\begin{array}{l}\text { Reinforcement } \\
\text { workers } \\
(n=252)(\%)\end{array}$ \\
\hline Femorotibial joint: & & \\
$\quad$ Osteophytes & 18 & 15 \\
$\quad$ Narrowing of joint space & 2 & 2 \\
$\quad$ Subchondral sclerosis & 2 & 1 \\
Femoropatellar joint: & 33 & 30 \\
$\quad$ Insertion periostosis & 11 & 10 \\
Osteophytes & 1 & 1 \\
$\quad$ Subchondral sclerosis & & \\
\hline
\end{tabular}

The most common clinical findings were crepitation and patellar tenderness. For no finding was there a significant difference between the two groups (table 3). The occurrence of both crepitation and patellar tenderness increased clearly with age.

On radiological examination, insertion periostosis in the femoropatellar joint was the most common finding. Osteophytes were found more commonly in the femorotibial joint than in the femoropatellar joint. No significant differences were found between reinforcement workers and painters (table 4).

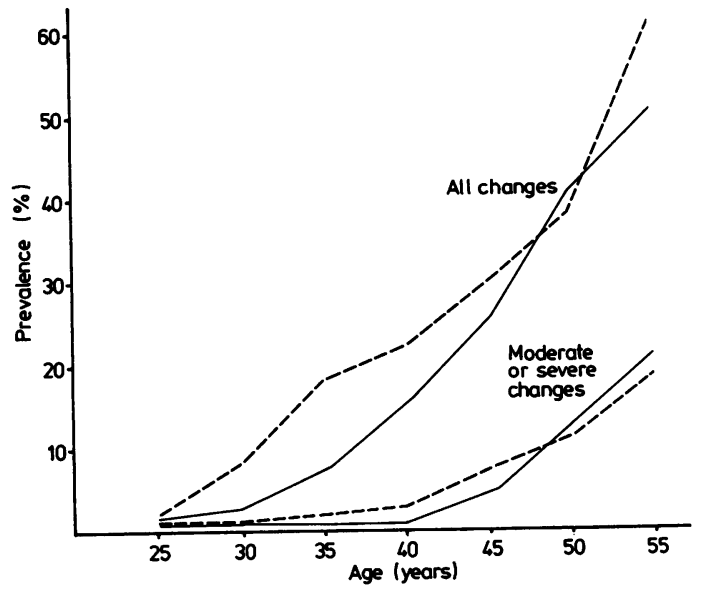

Prevalence (\%) of radiologically detectable degenerative changes in the knee joints by age in reinforcement workers $(--\rightarrow)$ and painters (-).

The degenerative changes (disregarding insertion periostosis) were summed up in each investigated worker so that he was classified according to the highest developed degree of degeneration found in any of the variables presented in table 4 . The result is presented in the figure, which shows the prevalence of degenerative changes by age. The radiologically detected degenerative changes in the knees were somewhat related to reported symptoms and observed clinical signs in both occupational groups. This association was a little stronger among the reinforcement workers than among the painters (table 5).

\section{Discussion}

The aim of the reinforcement worker study was to determine the possible effects of the mechanical loads in concrete reinforcement work on the musculoskeletal system of the workers. The primary question concerned the effect of reinforcement work on the back. Choosing the maintenance painters as the reference group for the reinforcement workers,

Table 5 Symptoms and clinical signs from the knees compared with radiologically detected degenerative changes in reinforcement workers and painters

\begin{tabular}{|c|c|c|c|c|}
\hline \multirow[t]{2}{*}{ Symptom or clinical finding } & \multicolumn{2}{|l|}{ Reinforcement workers } & \multicolumn{2}{|l|}{ Painters } \\
\hline & $\begin{array}{l}\text { No degenerative } \\
\text { changes }(n=196)(\%)\end{array}$ & $\begin{array}{l}\text { Degenerative changes } \\
(n=55)(\%)\end{array}$ & $\begin{array}{l}\text { No degenerative } \\
\text { changes }(n=184)(\%)\end{array}$ & $\begin{array}{l}\text { Degenerative changes } \\
(n=46)(\%)\end{array}$ \\
\hline $\begin{array}{l}\text { Pain or ache during preceding month } \\
\text { Stiffness during preceding month } \\
\text { Locking during preceding month } \\
\text { Crepitation } \\
\text { Patellar tenderness }\end{array}$ & $\begin{array}{r}19 \\
16 \\
6 \\
36 \\
16\end{array}$ & $\begin{array}{l}42^{* * *} \\
36 \\
13 \\
49 \\
38^{* * *}\end{array}$ & $\begin{array}{r}29 \\
18 \\
7 \\
31 \\
17\end{array}$ & $\begin{array}{l}37 \\
20 \\
9 \\
63^{* *} \\
28\end{array}$ \\
\hline
\end{tabular}


it was evident that the group did not differ from one another as much in regard to knee loads as to back loads.

The occupational factors responsible for meniscal lesions have been evaluated in several studies of coal mining. Lawrence ${ }^{15}$ did not find any occupational factor causally related to osteoarthrosis in the knee other than injury, and Atkins ${ }^{6}$ concluded that repeated specific trauma, together with personal susceptibility to knee joint lesions, best accounted for the common occurrence of knee derangements in miners. Sudden rotatory or abductory strain on semiflexed joints has been considered likely to cause semilunar cartilage injury, ${ }^{4}$ and Smillie ${ }^{9}$ states that a meniscus is seldom torn in the total absence of rotatory movement. Sharrard ${ }^{2}$ agrees that kneeling in itself cannot be shown to cause meniscal tears, but thinks that kneeling predisposes to joint instability by causing laxity of the ligaments, thus making the joint structures likely to sustain tears on other occasions. Better walking surfaces to diminish the risk of stumbling and slipping have been recommended by Sharrard and Liddell ${ }^{7}$ to diminish the occurrence of meniscal lesions. Owing to the increased mechanisation of the mines, a decline in meniscal lesions among coal miners has been observed both in Germany and Britain. ${ }^{89}$

When concrete reinforcement and maintenance painting work were analysed, it was found that in both trades there were significant loads on the knee joints. The biggest difference between them was in the handling of weights, which was clearly more common in reinforcement work.

The painters' work surroundings were more or less the same in all places of work. When the painter knelt or squatted his posture was mostly stable and he did not handle any significant weights in these postures. The biggest risk for knee injury was caused by climbing ladders and platforms.

The work surroundings of the reinforcement workers changed continuously. Also when kneeling and squatting the reinforcement workers handled heavy weights. Lifting and carrying weights, often on uneven surfaces, was quite common in reinforcement work.

In the interview on previous and present symptoms and in the clinical examination of the knee joints no significant differences were found between the reinforcement workers and the painters. Radiological signs of degeneration were also equally common in both groups, even if there was some indication that reinforcement work provoked more symptoms from degenerated knee joints than painting work.

Both groups reported the same occurrence of knee accidents during the preceding 12 months. In a special interview study, however, the reported incidence of minor injuries (defined as unexpected, sudden additional load on the knees causing no or less than one day of sick leave) was five times more common in reinforcement work than in painting. According to insurance company registers the work accidents affecting the legs are twice as common among reinforcement workers as among painters.

\section{References}

' Watkins JT, Hunt TA, Fernandez RHP, Edmonds OP. A clinical study of beat knee. Br J Ind Med 1958;15:105-9.

2 Sharrard WJW. Pressure effects on the knee in kneeling miners. Ann $R$ Coll Surg 1965;36:309-24.

${ }^{3}$ Ceelen-Bonn W. Pathologische Anatomie der Meniscusschäden. Archiv fur Orthopadische und Unfall-Chirurgie 1937;37:334-53.

4 Adamson WAD. Injuries of the cartilage in miners. Edinburgh Medical Journal 1946;53:37-45.

${ }^{s}$ Kellgren JH, Lawrence JS. Rheumatism in miners. Part II : $x$-ray study. Br J Ind Med 1952;9:197-207.

- Atkins JB. Internal derangement of the knee joint in miners. Br J Ind Med 1957;14:121-6.

7 Sharrard WJW, Liddell FDK. Injuries to the semilunar cartilages of the knee in miners. Br J Ind Med 1962;19:195-202.

${ }^{8}$ Springorum PW. Der Einfluss der Arbeitsweise auf Meniscusschäden bei Bergleuten. Monatschrift für Unfallheilkund 1969;72:477-81.

${ }^{9}$ Smillie IS. Injuries of the knee joint. 5th ed. Edinburgh: Churchill Livingstone, 1978.

${ }^{10}$ Schlomka G, Schröter G, Ochernal A. Über die Bedeutung der beruflichen Belastung fur die Entstehung der degenerativen Gelenkleiden. Z Gesamte Inn Med 1955;10:993-9.

1 Waris P, Hänninen K, Luopajärvi T et al. Concrete reinforcement workers $\longrightarrow$ maintenance house painters study. Part 2: Musculoskeletal findings. Report No 168. Helsinki: Institute of Occupational Health, 1980. (In Finnish).

12 Niskanen T, Merisalo T, Saari J. Concrete reinforcement workers-maintenance house painters study. Part 3: Musculoskeletal strain in work. Report No 169. Helsinki: Institute of Occupational Health, 1980. (In Finnish).

${ }^{13}$ Wickström G, Hänninen K, Kalliokoski P et al. Concrete reinforcement workers-maintenance house painters study. Part 1: Background, study design and central results. Report No 167. Helsinki: Institute of Occupational Health, 1980. (In Finnish).

14 Mantel N, Haenszel W. Statistical aspects of the analysis of data from retrospective studies of disease. J Natl Cancer Inst $1959 ; 22: 719-48$.

is Lawrence JS. Rheumatism in coal miners. Part III: Occupational factors. Br J Ind Med 1955;12:249-61. 